\title{
UCLA
}

InterActions: UCLA Journal of Education and Information Studies

Title

Book Review: Feminist and Queer Information Studies Reader Edited by Patrick Keilty and Rebecca Dean

Permalink

https://escholarship.org/uc/item/1381d29;

Journal

InterActions: UCLA Journal of Education and Information Studies, 10(2)

Author

Cifor, Marika L

Publication Date

2014

DOI

10.5070/D4102022742

\section{Copyright Information}

Copyright 2014 by the author(s). All rights reserved unless otherwise indicated. Contact the author(s) for any necessary permissions. Learn more at https://escholarship.org/terms 
Feminist and Queer Information Studies Reader edited by Patrick Keilty and Rebecca Dean. Sacramento, CA: Litwin Books, 2013. 700 pp. ISBN: 978-1936117-16-1.

In the Feminist and Queer Information Studies Reader, editors Patrick Keilty and Rebecca Dean make a significant intervention by bringing the field of information studies into critical and timely conversation with cultural studies methods and concerns. They focus on these methods and concerns as they relate primarily to gender and sexuality. The larger goal of the collection is to bring an end (finally) to the long-term domination of information studies by positivist scientific and behaviorist modes of inquiry. In order to do this work the Reader brings together diverse interdisciplinary voices to address a wide-ranging array of information and technology theories and practices as they pertain to the study of gender and sexuality. By putting essays by information studies scholars and by scholars not traditionally associated with the discipline side-by-side, the Reader sparks new dialogues, opening up information studies as a field and exposing others to its concerns. The Reader is a vitally important contribution to the Information Studies field, has broad ranging appeal, and will serve as an invaluable teaching and learning tool, inciting fruitful discussions for all those seeking to expand its traditional methodological and theoretical concerns and limitations.

The Reader is the fourth book in the Litwin Books series on gender and sexuality in information studies. It emerged out of the graduate work of the editors at the UCLA Departments of Information Studies and Gender Studies. It is a love note to the former's unusual and deep commitment to embracing cultural studies concerns and methods in consideration of the social, political, economic, and historical contexts of information and technology. Keilty is currently an Assistant Professor at the University of Toronto in the Faculty of Information and teaches at the Bonham Centre for Sexual Diversity Studies. Rebecca Dean is a gender and technology researcher working in the mobile software industry. The editors' backgrounds in gender studies and focuses on queer and feminist encounters with digital technologies set the tone for the collection. The selected authors represent diverse voices interested in and affected by issues of gender, sexuality, information, and technology. They are predominately academics at various stages of their careers, from doctoral students to senior faculty, working in disciplines including information studies, communication, media studies, gender and women's studies, and sexuality studies. There are also a few notable contributions for those outside of the academy from authors engaged with these issues in their art practices. The Reader does a fantastic job of pointing to just how many scholars of queer and feminist concerns speak to information studies, and conversely how well information studies scholars can speak beyond the discipline. The diversity of the 
authors represents that of the collection as a whole and is one of its greatest strengths.

An "antidote to the marginalization of cultural and humanistic inquiry" (Keilty, p. 5) the Reader presents twenty-seven essays that make queer and/or feminist interventions into the study of information. A mixture of previously published pieces and unpublished new works, the collection is not intended to be a comprehensive look at these topics, but rather should serve a as teaching tool that can and should be supplemented to address the concerns of particular courses, audience, and instructors. The tone of the reader is set forth in a foreword by Sandy Stone and the introduction by Keilty. The collection is structured is into seven parts: Information as Gendered Labor; Cyborgs and Cyberfeminism; Online Environment; Information Organization; Information Extraction, Information Flow; Archive; and Performance. These sections are topical and push at the confines of traditional areas of study within information studies. With a careful reading, it is still possible to make connections between these topics, particular essays, and traditional areas of inquiry particularly information seeking and policy. An afterword by Leah A. Lievrouw points to the broad themes and key contributions outlined in the collection. The Reader speaks to concerns of information studies broadly for an interdisciplinary audience. However, in its framing it seems to narrow its attention contradictorily to serving as a pedagogical tool for an academic audience of faculty and graduate students within information studies only. This framing does an injustice to the Reader overlooking its potential to address academic audiences outside of information studies as well as practitioners within the field.

The beautiful and tremendous range of essays and the "crosstalk, harmonies and dissonances among them" (Stone, p. xvi) are sure to pique the interest of many readers. There is the potential for great joy for the reader in making new discoveries and rediscovering classic pieces in a new context. I found myself equally enthralled by new works such as Melissa Adler's "Paraphilias: The Perversion of Meaning in the Library of Congress Catalog" and Danielle Cooper's "'Welcome Home': An Exploratory Ethnography of the Information Context of at the Lesbian Herstory Archives" as by making new connections and gaining deeper understandings in rereading now classic pieces such as Jasbir Puar's "On Torture: Abu Ghraib" and Dean Spade's "Administering Gender." Together the essays confirm the importance of the examination of gender and sexuality to within information studies and the importance of these works to making the field more critical. As with every collection of essays there is some unevenness in the contributions, however the quality of the selections overall is very high and deeply compelling.

My primary critique of the Reader on its own terms is that it could have been further developed as a pedagogical tool. The concept of information and the field of information studies are very effectively developed in the introduction, 
making it clear to readers of all backgrounds the necessity for the work this collection does. Information is necessarily very broadly conceived and is always seen as situational and contingent. There is also a commendable conscious effort on the part of the editors in the selection of essays and by individual authors to acknowledge the complex intersections of concerns of race, gender, sexuality, socio-economic status, and other "identity-fracturing" and "identity constituting discourses" (Keilty, p. 6). Unfortunately there is no similar effort on the part of the editors to provide specific contextualization for the use of the terms feminist or queer. Greater contextualization of these terms by providing brief histories as Keilty did for information and information studies in the introduction would have been useful for readers, especially those less familiar with these disciplines and their questions and modes of inquiry. As a pedagogical tool it also would have been useful for the editors to introduce each of the seven topical sections in order to explain briefly the thinking behind that section and some of the connections and dissonances of the essays therein. This greater contextualization overall would be useful for all readers, but particularly so for instructors who may use this Reader as a pedagogical tool.

Beyond the contributions made by the collection to demonstrating the central place of feminist and queer theories, as well as gender and sexuality more broadly to information studies, the Reader succeeds in achieving its primary goal: making a critical intervention into Information Studies. The need for more and deeper cultural and humanistic inquiry in the field should be clear to all who take up the Reader. The Reader has made a tremendous step towards ending the domination of positivist scientific and behaviorist modes of description in Information Studies. It is sure to inspire future work in these modes in the classroom and beyond.

\section{Reviewer}

Marika Cifor is a doctoral student in Information Studies at the UCLA, where she is also pursuing a Concentration Certificate in Gender Studies. She holds a MS in Library and Information Science with a Concentration in Archives Management and an MA in History from Simmons College and a BA in History and Political, Legal, and Economic Analysis from Mills College. Her research interests include archives, affects, queer and feminist theories, and LGBTQ histories. 